\title{
Application of remote sensing-based two-source energy balance model for mapping field surface fluxes with composite and component surface temperatures
}

Lisheng Song ${ }^{\mathrm{a}, \mathrm{b}}$, Shaomin Liu ${ }^{\mathrm{a} *}$, William P. Kustas ${ }^{\mathrm{b}}$, Ji Zhou ${ }^{\mathrm{c}}$, Ziwei Xu ${ }^{\text {a }}$, Ting Xia ${ }^{\mathrm{d}, \mathrm{b}}$, Mingsong Li ${ }^{\mathrm{c}}$

${ }^{a}$ State Key Laboratory of Remote Sensing Science, School of Geography, Beijing Normal University, Beijing 100875, China

${ }^{\mathrm{b}}$ U.S. Department of Agricultural, Agricultural Research Service, Hydrology and Remote Sensing Lab, Beltsville, $M D, 20705, U S A$

c School of Resources and Environment, University of Electronic Science and Technology of China, Chengdu 611731, China

d Department of Hydraulic Engineering, Tsinghua University, Beijing, 100084, China

\section{Revised Manuscript}

*Corresponding author and address:

Dr. Shaomin Liu

State key laboratory of Remote Sensing Science, School of Geography

Beijing Normal University

No.19, Xinjiekouwai Street

Beijing 100875, China

Tel: 86-10-58802240

Fax: 86-10-58805274

E-mail: smliu@bnu.edu.cn

Dr. William P. Kustas

U.S. Department of Agricultural, Agricultural Research Service, Hydrology and Remote Sensing Lab, Beltsville, MD, 20705, USA

Tel: 1-301- 504-8498

Fax: 1-301-504-8931

E-mail:Bill.Kustas@ars.usda.gov 
Abstract: Operational application of a remote sensing-based two source energy balance model (TSEB) to estimate evaportranspiration (ET) and the components evaporation (E), transpiration (T) at a range of space and time scales is very useful for managing water resources in arid and semiarid watersheds. The TSEB model uses composite land surface temperature as input and applies a simplified Priestly-Taylor formulation to partition this temperature into soil and vegetation component temperatures and then computes subsequent component energy fluxes. The remote sensing-based TSEB model using component temperatures of the soil and canopy has not been adequately evaluated due to a dearth of reliable observations. In this study, soil and vegetation component temperatures partitioned from visible and near infrared and thermal remote sensing data supplied by advanced scanning thermal emission and reflection radiometer (ASTER) are applied as model inputs $\left(\mathrm{TSEB}_{\mathrm{CT}}\right)$ to assess and refine the subsequent component energy fluxes estimation in TSEB scheme under heterogeneous land surface conditions in an advective environment. The model outputs including sensible heat flux $(H)$, latent heat flux $(L E)$, component $L E$ from soil and canopy from the $\operatorname{TSEB}_{\mathrm{CT}}$ and original model $\left(\mathrm{TSEB}_{\mathrm{PT}}\right)$ are compared with ground measurements from eddy covariance (EC) and larger aperture scintillometers (LAS) technique, and stable isotopic method. Both model versions yield errors of about $10 \%$ with $L E$ observations. However, the $\mathrm{TSEB}_{\mathrm{CT}}$ model output of $H$ and $L E$ are in closer agreement with the observations and is found to be generally more robust in component flux estimation compared to the $\mathrm{TSEB}_{\mathrm{PT}}$ using the ASTER data in this heterogeneous advective environment. Thus given accurate soil and canopy temperatures, $\mathrm{TSEB}_{\mathrm{CT}}$ may provide more reliable estimates of plant water use and values of water use efficiency at large scales for water resource management in arid and semiarid landscapes.

Keywords: Evaporation and transpiration, composite and component temperatures, TSEB $\mathrm{CT}_{\text {, }}$ validation 


\section{Introduction}

Accurate estimates of evapotranspiration (ET) have a wide range of applications in hydrology, climate, weather and crop yield forecasting, drought monitoring, and water resource management. What's more, accurate partitioning of ET into evaporation $(E)$ and transpiration $(T)$, permits the evaluation of how much irrigated water is beneficial to the plants growth compared with non-beneficial water loss from the surface soil (Pereira et al., 2015). Knowledge of this partitioning can foster the development of more efficient irrigation management practices and engineering designs. Ground-based measurements from lysimeters or from eddy covariance flux tower observations can provide representative values of ET at field scale and with high frequency eddy covariance data it's partitioning into $E$ and $T$ under certain environmental conditions (Scanlon and Kustas, 2012). But such local ET observations are difficult to scale up to watershed, and regional scales, due to natural variability at the landscape scale of soil properties and vegetation type, as well as hydrometeorological conditions which includes local weather, and soil moisture conditions (Choi et al., 2009).

To address the need for large scale spatially distributed ET, several remote sensing based approaches using the satellite-based thermal infrared (TIR) and visible and near infrared (VNIR) imagery have been developed and refined in recent years (Kustas and Anderson, 2009). One set of approaches involve one-source models (OSM) applied in contextual approach with remote sensing imagery to define hydrologic extremes (wet/cool and hot/dry conditions) (Allen et al., 2007; Bastiaanssen et al., 1998; Su, 2002). Compared with the OSM-contextual based approaches, the two-source energy balance model (TSEB) is more physical-based since the parameterizations explicitly treat the radiative temperature and energy exchanges between soil and vegetation, and soil-vegetation-atmosphere interface (Kustas and Norman, 1999; Norman et al., 1995). The TSEB model partitions the composite surface radiometric temperature and energy fluxes into soil and vegetation temperatures and fluxes. It not only can produce more reliable flux estimates than OSM techniques, particularly for heterogeneous surfaces with partial vegetation 
cover, but also TSEB partitions the fluxes and ET in particular into soil $(E)$ and vegetation $(T)$ components which is useful information for identifying plant stress from changes in $T$ than changes in surface moisture affecting only $E$ (Kustas and Anderson, 2009).

There have been great advances in the application of thermal infrared remote sensing for using the TSEB model to estimate land surface $E T$ and its component of $E$ and $T$. However, errors in estimation of land surface temperature and near surface air temperature can significantly degrade the accuracy of the TSEB model which is quite sensitive to uncertainty in surface-air temperature differences. To address this limitation, several time-differencing techniques such as ALEXI (Atmosphere-Land Exchange Inverse) (Anderson et al., 1997), DisALEXI (an ALEXI flux disaggregation approach) (Norman et al., 2003) and DTD (Dual-Temperature Difference) (Norman et al., 2000) models based on the TSEB model framework, have been shown to minimize the impacts of inevitable uncertainties in the land surface and air temperatures (Kustas and Anderson 2009). The TSEB modeling framework in addition applies the Priestley-Taylor equation with the coefficient $\alpha$ usually assumed to have a value $\sim 1.3$ to initially estimate vegetation temperature. There is a iteration procedure to adjust the value of $\alpha$ in cases where estimated $E<0$ under daytime conditions due to an overestimated soil surface temperature indicating plants are likely under water stress and should have an elevated canopy temperature. However, under well watered and in strongly advective conditions where a higher value of $\alpha$ may be more appropriate, this cannot be derived apriori (Kustas and Norman, 1999). Refinements to the TSEB modeling parameterizations such as using Penman-Monteith formulation for estimating the vegetation temperature have been proposed (Colaizzi et al., 2012a), which can provide a more accurate partitioning between soil $E$ and canopy $T$ than in the original TSEB model, but requiring near-surface vapor pressure and knowledge of stomatal resistance makes it difficult to be applied operationally at large scales using satellite data.

Although the TSEB model and refinements to it have been applied and evaluated under a wide variety of vegetation types, vegetation coverage, climates and spatial 4 
scales (Colaizzi et al., 2012a), there have been very few studies that have evaluated the TSEB model using the component soil and vegetation temperatures from the infrared radiometers (Colaizzi et al., 2012a; Sánchez et al. 2008, 2015) and also the partitioned fluxes $E$ and $T$ (Colaizzi et al., 2012a; Agam et al. 2012). A major reason for the lack of such studies is the difficulty in obtaining reliable soil and vegetation temperatures (accounting for both shaded and sunlit soil and vegetation temperatures) and in measuring $E$ and $T$ that are representative at the micrometeorological scale (Colaizzi et al., 2012a; Song et al., 2015a).

In this paper, the remote sensing based TSEB model is evaluated with composite and component temperatures as input. The modeled $E T$ and its component $E$ and $T$ are evaluated with tower measurements from the eddy covariance system and the stable oxygen and hydrogen isotopes approach. Additionally, the model output of sensible heat flux was assessed under heterogeneous land surface conditions using Large Aperture Scintillometers (LAS) measurements. In this paper, evaluation of ET and $T$ and $E$ and $H$ output from TSEB model is performed during a growing season, in an irrigated semiarid agricultural location, under strongly advective conditions. This provides greater insight into the capability of the TSEB to accurately partition ET into its soil and plant canopy contributions under such conditions.

\section{Methodology}

The key boundary condition for remote sensing based TSEB model is the land surface temperatures (Kustas and Anderson, 2009). The model originally proposed by Norman et al., (1995) has undergone several refinements which include improving net radiation partitioning between soil and canopy elements and soil surface resistance formulation (Colaizzi et al., 2012b; Colaizzi et al., 2012c; Kustas and Norman, 1999, 2000), the reference air temperature estimation at the regional scale(Anderson et al., 1997; Norman et al., 2000; Cammalleri et al., 2012), the temperature partitioning between soil and canopy and use of the Penman-Monteith as opposed to the Priestley-Taylor formulation for $T$ (Colaizzi et al., 2012a). In the TSEB model the satellite derived directional surface temperature, $T_{R}(\theta)$ is related to the soil and vegetation component temperatures, based on the fraction of vegetation 
cover viewed by the radiometer at viewing angle $\theta$ (Kustas and Anderson, 2009), expressed as:

$$
T_{R}(\theta) \approx\left[f_{c}(\theta) T_{c}^{4}+\left(1-f_{c}(\theta)\right) T_{s}^{4}\right]^{1 / 4}
$$

where $T_{c}$ and $T_{s}$ are component temperatures $(\mathrm{K})$ in the pixel, and $f_{c}(\theta)$ is the fraction of vegetation coverage observed at the view zenith angle $(\theta)$ by the thermal sensor. These component temperatures when combined with the available energy for the soil and canopy system compute the relevant turbulent fluxes from the soil and canopy elements (Colaizzi et al., 2012a; Colaizzi et al., 2012b; Kustas and Anderson, 2009):

$$
\begin{gathered}
R n_{s}=H_{s}+L E_{s}+G_{0} \\
R n_{c}=H_{c}+L E_{c} \\
R n_{s}=\tau_{\text {longwave }} L_{\downarrow}+\left(1-\tau_{\text {longwave }}\right) \varepsilon_{c} \sigma T_{c}^{4}-\varepsilon_{s} \sigma T_{s}^{4}+\tau_{\text {solar }}\left(1-\alpha_{s}\right) S_{\downarrow} \\
R n_{c}=\left(1-\tau_{\text {longwave }}\right)\left(L_{\downarrow}+\varepsilon_{s} \sigma T_{s}^{4}-2 \varepsilon_{c} \sigma T_{c}^{4}\right)+\left(1-\tau_{\text {solar }}\right)\left(1-\alpha_{c}\right) S_{\downarrow}
\end{gathered}
$$

where $R n$ is net radiation ( $\left.\mathrm{W} \mathrm{m}^{-2}\right), G_{0}$ is surface soil heat flux $\left(\mathrm{W} \mathrm{m}^{-2}\right)$, and $H$ and $L E$ are the sensible and latent heat fluxes $\left(\mathrm{W} \mathrm{m}^{-2}\right), \varepsilon, \alpha$, are the emissivity and albedo, respectively; the subscripts $c$ and $s$ refer to the canopy and soil, respectively. $S_{\downarrow}$ and $L \downarrow$ are the incoming shortwave and longwave radiation $\left(\mathrm{W} \mathrm{m}^{-2}\right)$ from the sky, $\tau_{\text {longwave }}$ and $\tau_{\text {solar }}$ are the longwave and shortwave radiation transmittances through the canopy, respectively.

By allowing the interaction between the soil and vegetation fluxes in the soil and vegetation combined system, the series version of TSEB model proposed by Norman et al., (1995) is a more realistic parameterization of the energy exchange between the soil and canopy components. The model expresses $H_{s}$ and $H_{c}$ as a function of surface-air temperature difference between the surfaces of soil and vegetation and in the vegetation layer, respectively:

$$
H_{s}=\rho C_{p} \frac{T_{s}-T_{a c}}{R_{S}}
$$




$$
H_{c}=\rho C_{p} \frac{T_{c}-T_{a c}}{R_{X}}
$$

Where $\rho$ is the air density $\left(\mathrm{kg} \mathrm{m}^{-3}\right), C_{p}$ is the specific heat of air $\left(\mathrm{J} \mathrm{kg}^{-1} \mathrm{~K}^{-1}\right), T_{a c}$ is the air temperature in the vegetation air layer, $R_{S}$ is the resistance to heat flow in the boundary layer immediately above the soil surface $\left(\mathrm{s} \mathrm{m}^{-1}\right), R_{X}$ is the total boundary layer resistance of the complete canopy of leaves $\left(\mathrm{s} \mathrm{m}^{-1}\right)$.

To estimate the component surface fluxes from the soil and vegetation, the Priestley-Taylor and parallel resistance formulations are combined, and the initial vegetation temperature is computed as (Norman et al., 1995):

$$
T_{c i}=T_{a}+\frac{R n_{c} r_{A H}}{\rho C_{p}}\left[1-\alpha_{P T} f_{G} \frac{\Delta}{\Delta+\gamma}\right]
$$

where $T_{c i}$ is the initial estimate of $T_{c}, T_{a}$ is the air temperature at the reference height, $r_{A H}$ is the aerodynamic resistance to turbulent heat transport between the canopy source height and the reference height $\left(\mathrm{W} \mathrm{m}^{-2}\right)$. The value of $\alpha_{P T}$ for the canopy transpiration under non-stressed conditions is assumed to have a value $\sim 1.26$ derived from the original Priestley-Taylor formulation (Priestley and Taylor, 1972), except perhaps under well-watered vegetation cover conditions in strongly advective environments where $\alpha_{P T}$ may approach a value on the order of 2 (Kustas and Norman, 1999). The variable $f_{G}$ is the fraction of green vegetation, $\Delta$ is the slope of the saturation vapor pressure versus temperature curve and $\gamma$ is the psychrometric constant of $\sim 0.06$. Once $T_{\mathrm{c}}$ is computed, soil temperature is derived using the Stefan-Boltzmann law for the soil and vegetation system via Eq. (1). The value of $\alpha_{P T}$ can be decreased under the water stress conditions (Kustas et al., 2004), but increasing $\alpha_{P T}$ for under advective conditions cannot be done a priori (Agam et al., 2010). In the TSEB framework, the $\alpha_{P T}$ value is adjusted to decrease eventually the $E$ greater than zero where the surface is not completely dry. After initial application of the parallel resisitance formulation in TSEB in combination with the Priestley-Taylor formulation for estimating a first estimate of vegetation temperature from the composite radiometric surface temperature, the series resistance framework is applied subsequently to adjust the component temperatures and fluxes at each iteration in 7 
order to obtain radiative temperature and surface energy of the soil-vegetation system balance. If soil and canopy temperatures are available, then there is no need for the Priestley-Taylor formulation and the heat fluxes from the soil and canopy can be derived directly with the additional resistance formulation

$$
H=\rho C_{p} \frac{T_{a c}-T_{a}}{R_{A}}
$$

where $R_{A}$ is the aerodynamic resistance between the air-canpy layer and is computed according to Kustas and Norma (1999). Thus TSEB can be run using the Priestley-Taylor formulation $\left(\mathrm{TSEB}_{\mathrm{PT}}\right)$ with a composite surface temperature or with the component temperature observations $\left(\mathrm{TSEB}_{\mathrm{CT}}\right)$. The latent heat fluxes from the soil and vegetation surface are solved as a residual in their energy balance equation, respectively:

$$
\begin{gathered}
L E_{s}=R n_{s}-H_{s}-G_{0} \\
L E_{c}=R n_{c}-H_{c}
\end{gathered}
$$

with $G_{0}$ computed as a fraction of the net radiation at the soil surface:

$$
G=c_{G} R n_{s}
$$

The value of $c_{G}$ varies to some degree with soil type and moisture conditions and also in time. However, for many soil type and moisture states with satellite overpass times occurring midmorning to early afternoon, the value of $c_{G}$ is assumed to be constant value equaling 0.3 (Kustas, et al, 1998).

The typical source area (flux footprint) relevant to EC tower measurements is largely controlled by the height of EC instrumentation above the canopy, local wind speed and direction, surface roughness and atmospheric stability; this results in the source area contributing to the flux ranging in size from $10^{2} \mathrm{~m}^{2}$ to $10^{4} \mathrm{~m}^{2}$. The surface heat fluxes estimated from the ASTER images have a pixel resolution of $90 \mathrm{~m}$, which means that the contributing source area is likely to cover multiple pixels. Therefore a two-dimensional flux footprint model was used to derive the weighted source area contributing to EC tower footprint (Hsieh et al., 2000), and subsequently 
used with the $90 \mathrm{~m}$ resolution model output and associated pixel weights for integrating gridded $\mathrm{TSEB}_{\mathrm{CT}}$ and $\mathrm{TSEB}_{\mathrm{PT}}$ fluxes to the EC footprint scale (Jia et al., 2012).

\section{Study area and data collection}

The two versions of the TSEB model $\left(\right.$ TSEB $_{\mathrm{PT}}$ and TSEB $_{\mathrm{CT}}$ ) were evaluated using the remote sensing VNIR and TIR, ground observed meteorology, fluxes data and measured auxiliary data are collected from the Multi-Scale Observation Experiment on Evapotranspiration over heterogeneous land surface which was part of the Heihe Water Allied Telemetry Experimental Research (HiWATER-MUSOEXE) (Li et al., 2013; Xu et al., 2013). The HiWATER-MUSOEXE including a flux observation network which composed of two nested matrices: one large experimental area $(30 \mathrm{~km} \times 30 \mathrm{~km})$ and one kernel experimental area $(5.5 \mathrm{~km} \times 5.5 \mathrm{~km})$ was conducted in the middle reaches of the Heihe River Basin (Zhangye, Gansu, China) where the land is mainly comprised of corn, desert, desert steppe, Gobi, vegetable crops, orchards, and some residential areas. The period of study encompassed May to September in 2012 during which the land surface had a wide range of vegetation cover conditions. The flux observation network is comprised of 17 flux tower installations across the $5.5 \mathrm{~km} \times 5.5 \mathrm{~km}$ study area to capture spatio-temporal dynamics in energy, water and carbon fluxes and was used to evaluate the remote sensing based TSEB models.

\subsection{Ground-based fluxes and meteorological data collection}

During the HiWATER-MOSEXE, 14 eddy covariance (EC) flux towers were installed in corn fields under different planting dates and irrigation schedules while the remaining three towers were installed in a vegetable (pepper) crop (site 1), residential area (site 4) and in an apple orchard (site 17), respectively, (Figure 1). At each EC flux tower, there was an automatic weather station (AWS) collecting meteorological data (Four-component radiation, soil heat flux, air temperature and humidity, wind speed/direction, precipitation, air pressure, soil temperature and moisture profile, etc.). 
To quantifying the measurement uncertainty associated with each surface energy flux measurement system, the 21 EC systems, 7 LAS pairs and 18 4-way radiometers which were being deployed over a uniform field site within the HiWATER-MOSEXE domain (in Bajitan Gobi desert, west of Zhangye City) and measurements collected from $14^{\text {th }}$ to $24^{\text {th }}$ May, 2012. The results indicate that the measurements from all the instrumentation are in close agreement having differences within $10 \%$ under such homogeneous conditions. The details of instrument inter-comparison and instrument performance are described by Xu et al. (2013).

The recorded raw data from the EC system were processed using the Edire software and finally averaged over $30 \mathrm{~min}$, the details of data processing, gap filling and refining can refer to (Liu et al., 2011; Liu et al., 2013). The uncertainties from the EC system during HiWATER-MUSOEXE were estimated to be nearly $20 \%$ for $H$ and around $15 \%$ for $L E$, respectively (Wang et al., 2015). The energy balance closure were enforced in the EC system observations by preserving the observed Bowen ratio $H / L E$ and residual approach (Twine et al., 2000). In addition, four groups of optical LAS systems (eight pairs with two LAS systems per group) were installed and designed to sample an area representative of a $3 \times 3$ (LAS1, LAS2 and LAS3) and 2 $\times 1$ (LAS4) Moderate-resolution Imaging Spectroradiometer (MODIS) image pixel, as shown in Fig. 1., and details including type, height, path length and data processing are given in Liu et al. (2015). The surface soil heat flux was calculated from the heat-plats (two under bare soil and one under vegetation) measurements, combined with the PlateCal approach proposed by Liebethal et al. (2005).

The local meteorological data including near surface air temperature, wind speed, vapor pressure, air pressure and incoming shortwave radiation came from the flux towers were processed to 30 min averages. The data were refined by gap filling using the linear interpolation and rejecting outliers. To derive the spatial distributions of these parameters which are required in the TSEB model, the point observation were interpolated using the inverse distance weighted method with the pixel resolution of $90 \mathrm{~m}$ (Ma et al., 2015). 


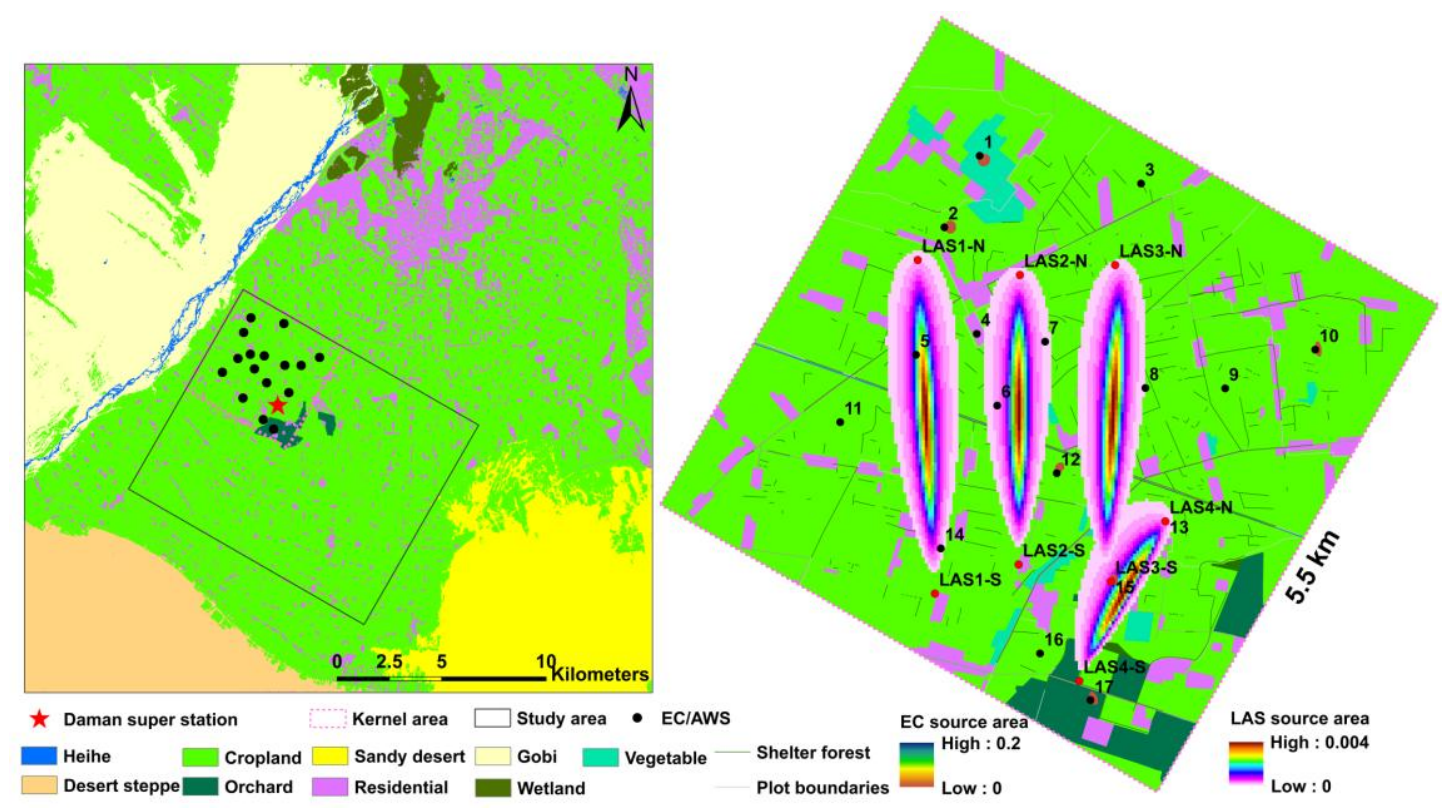

Fig. 1. Schematic showing the location of eddy covariance systems (EC)/automatic weather stations (AWS) and associated land covers, the instantaneous source area (flux footprint) for selected EC towers and LAS towers on DOY176 in the study.

At station 15 in a corn field (Daman superstation), the isotopic composition of water vapor in surface air was measured from a cavity ring-down spectroscopy (CRDS) water vapor isotope (Model L1102-I, Picarro Inc) (Huang and Wen, 2014; Wen et al., 2015), and isotopic composition was also measured from the sampling at station 13 also in a corn field during the HiWATER-MUSOEXE. Details of the isotope experiment, its principle of operation, and its calibration procedure in this study are given by Huang and Wen (2014), Wen et al. (2015). To satisfy the measurements of the ambient air sample two intakes of the eight-way solenoid valve were chosen, the heights of the intakes were 0.5 and $1.5 \mathrm{~m}$ above the corn canopy, which were controlled by an electric signal from Model L1102-I (Huang and Wen 2014). Then the $E(\delta \mathrm{E})$ can be estimated based on the Craig-Gordon model and $T(\delta \mathrm{T})$ is usually approximated by the $\delta \mathrm{D}$ and $\delta^{18} \mathrm{O}$ of the water in xylem or stem assuming the isotopic state is satisfied, however the isotopic state only likely appear during the midday in field conditions (Wen et al. 2015). Considering water vapor as a mixture of ET from an ecosystem carries unique isotopic signals from plant transpiration and soil evaporation separately, and based on water and isotope mass balance, introducing Keeling plot method and Craig-Gordon model, the measured isotopic composition of 11 
water was used to partition $E T$ in to $E$ and $T$ (Hu et al., 2014; Wen et al., 2012; Wen et al. 2015). The partitioning results are consistent with daily $E$ estimates from lysimeter measurements collected during the growing season, but have larger discrepancies after an irrigation event occurred. However, since the ground observations of $\delta_{\mathrm{ET}}, \delta_{\mathrm{E}}$, $\delta_{\mathrm{T}}$ can be affected by rainfall, irrigation and strong advection which can introduce significant uncertainty in ET partitioning (Huang and Wen, 2014; Wen et al. 2015), a subset of the data deemed reliable according to the satellite overpass time are used in the current study.

\subsection{Satellite data collection}

ASTER Level 1B products (after radiometric calibration and geometric correction) including VNIR and TIR bands were collected and were radiometrically calibrated (DOY 167, 176, 192, 215, 224, 231, 240, 247, 256). Although ASTER standard level 2B products containing land surface temperature (LST) and emissivity have been widely used, problems always arise in high and low spectral contrast (maximum-minimum difference), which could cause errors in LST estimation. Here, using the estimated surface emissivity from the ASTER Normalized Difference Vegetation Index (NDVI) data (Sobrino et al., 2004) and atmospheric profile measured from Zhangye Meteorological Observation through radiosounding at satellite overpassed time, combining the radiative transfer equation, the spatial distribution of land surface temperatures were derived from ASTER VNIR and TIR data (Zhou et al. 2015). The ASTER LST were compared to the ground-based temperatures computed from the four-component radiometers and component surface emissivities in the field of view of radiometers from FT-IR spectrometer(102 F) combining with Iterative Spectrally Smooth Temperature Emissivity Spectrometer (ISSTES) (Mu et al., 2013). The statistics illustrated the retrieved LSTs have a good agreement with the ground-based temperatures with a mean root mean square error (RMSE) of about 1.4-1.5K at the homogenous observation sites (Fig. 2) (Zhou et al., 2015). 


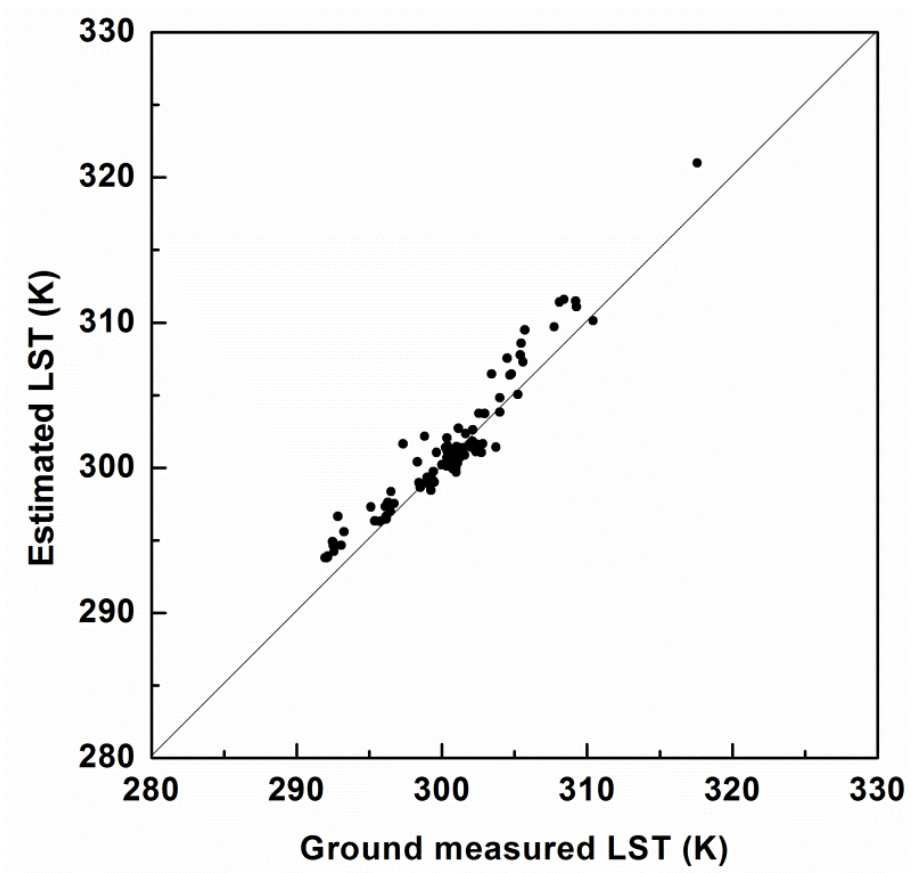

Fig. 2. Comparison between modeled and estimated land surface temperature (LST) for the homogenous surface.

The soil and vegetation component temperatures were partitioned using the land surface and albedo space approach derived according to the mono-surface energy balance (SEB-1) model from the ASTER TIR and VNIR data (Song et al., 2015b). This model partitions the composite temperature estimated from ASTER TIR data into soil and vegetation component temperatures by incorporating soil wetness iso-lines for defining equivalent soil temperatures. This allows the vegetation temperatures to be derived based on the Stefan-Boltzmann law combining with the fraction of vegetation cover. A comparison between the estimated and measured/interpolated component temperatures from ground-based sensors demonstrated a good agreement with a mean bias (i.e., estimated-measured-) and RMSE values of $-0.26 \mathrm{~K}$ and $0.83 \mathrm{~K}$, respectively for soil temperatures, and a bias and RMSE values of $-1.29 \mathrm{~K}$ and $1.64 \mathrm{~K}$ for vegetation temperatures (Song et al., 2015b).

Land surface albedo was estimated as a linear combination of ASTER waveband reflectances based on the approach proposed by Liang (2001), The non-snow/ice surface albedo computation formulation was given as following:

$$
\alpha=0.0771 \alpha_{1}+0.3652 \alpha_{2}+0.4086 \alpha_{3}+0.0178
$$


where $\alpha_{1}, \alpha_{2}$ and $\alpha_{3}$ are the surface albedos of the VNIR channels, respectively. The results have a good agreement with a mean bias (overestimate) of 0.004 , a mean absolute percent difference of $2.6 \%$ when compared to the ground measurements from the four-component radiometers.

\section{Results}

The availability of well-calibrated VNIR and TIR images allowed us to evaluate the capability of both models to reproduce surface energy fluxes and partition evapotranspiration into soil evaporation and plant transpiration. Evaluating the performance of the $\mathrm{TSEB}_{\mathrm{PT}}$ and $\mathrm{TSEB}_{\mathrm{CT}}$ models involved comparing modeled fluxes and partitioned evaporation and transpiration at the time of satellite overpasses with measured fluxes from the EC system and LAS towers and evaporation and transpiration measurements using the stable isotopic technique. In addition, a model intercomparison was conducted which included comparing the spatial distribution and magnitude of ET from the satellite imagery.

\subsection{Comparison with flux measurements}

As observed in many studies, the sum of turbulent flux measurements $H$ and $L E$ from $\mathrm{EC}$ towers tend to be less than the available energy, $\mathrm{Rn}-\mathrm{G}_{0}$. The non-enclosure phenomena is caused by many local and non-local factors (Foken, 2008) as well as the different spatial sampling of the EC sensors for the turbulent fluxes $H$ and $L E$, versus the local measurements made by the four-component radiometers for $\mathrm{Rn}$ and heat flow and soil temperature sensors and heat flux plates for determining soil heat flux. Recently, it was found that the non-closure of the energy balance was explained by the energy fluxes from secondary circulations and larger eddies that cannot be captured by EC measurement at a single station (Foken et al., 2011). Since the two models assume surface energy balance closure, the observed turbulent fluxes were forced to achieve closure by the Bowen ration and residual approaches. The residual method (assigning the missing flux to $L E$ ) only gave similar results for the corn sites but very different results for the residential site where $\mathrm{H}$ was much greater. The scatter plots in Figure. 3 illustrates comparisons of model fluxes from the TSEB $\mathrm{PT}_{\mathrm{P}}$ 
and TSEB ${ }_{\mathrm{CT}}$ at the time of the ASTER overpasses for nine clear-sky days (DOY 167, $176,192,215,224,231,240,247,256)$ with the measurements from the tower network. 

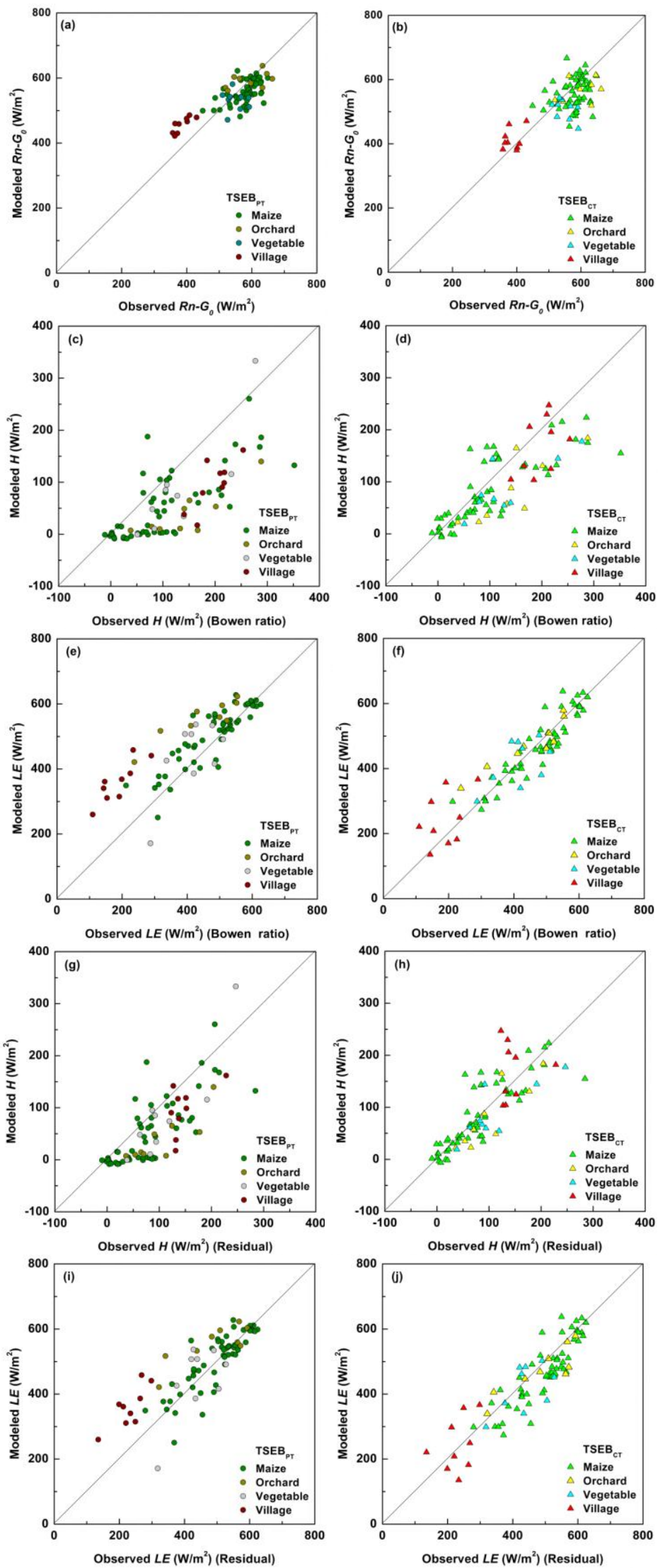

Fig. 3. Comparison of surface heat fluxes observed from EC systems and modeled from TSEB ${ }_{\mathrm{PT}}$ and TSEB $_{\mathrm{CT}}$ during the HiWATER experiment at times of ASTER overpass. 
Overall differences between $\mathrm{TSEB}_{\mathrm{PT}}$ and $\mathrm{TSEB}_{\mathrm{CT}}$ output and the measured fluxes are listed in Table 1. $\mathrm{TSEB}_{\mathrm{CT}}$ tended to have better agreement with the EC measurements, particularly for $H$ and $L E$, while there were similar differences between modeled versus measured available energy $R n-G_{0}$ using either TSEB ${ }_{\mathrm{PT}}$ or TSEB $_{\mathrm{CT}}$ (Fig. 3a, b). In Fig. 3a, b there is greater scatter between measured and modeled $R n-G$ for both models for the residential site, which is due in part to the fact that the net radiometer for this site have a field of view (FOV) of about $45 \mathrm{~m}$ while the $90 \mathrm{~m}$ pixel encompassed vegetation/land use conditions outside the $45 \mathrm{~m}$ radiometer footprint.

The greater scatter between modeled and measured $G_{0}$ from the two models are comparable (see Table 1) and reflect the fact that there is a major mismatch in scale between the area sampled by the soil heat flux sensors $(0.1 \sim 1 \mathrm{~m})$ and the $90 \mathrm{~m}$ resolution of model outputs. In addition, the larger mean absolute percentage (MAP) values is caused by the relatively small magnitude and range in the observed values for the most ground measurement sites which were under relatively high fractional vegetation cover and irrigated.

For the sensible heat flux $H$, difference between the TSEB $_{\mathrm{CT}}$ and TSEB $\mathrm{TT}_{\mathrm{PT}}$ output versus EC measurements illustrated in Fig. 3c, d, g, h and difference statistics listed in Table 1 indicate a fairly large underestimate, particularly for the $\operatorname{TSEB}_{\mathrm{PT}}$ when applying the Bowen ratio closure method for the EC measurements. For both models, differences with the measurements tend to be larger for the residential and orchard sites compared to the other sites when forced closure using the Bowen ratio method was applied to the EC measurements because this closure method significantly enhances the magnitude of $H$ particularly for the residential site. This is caused by the much higher value of Bowen ratio for the EC system for the residential site with average values of 1.2, compared to corn sites where the average Bowen ratio value was 0.3, while much larger roughness affecting TSEB under orchard sites. However, overall, the $\mathrm{TSEB}_{\mathrm{CT}}$ output of $H$ is in closer agreement with the measurements. The MAP values from two models are greater than the uncertainty in the measurements in this study area ( 20\%) (Wang et al., 2014), but the MAP values are greatly 17 
exaggerated mainly due to the very low values in measured $H$ from the irrigated corn crop which often occurs during mid-season with high vegetation cover and strong advection.

Table 1. Difference statistics between $\mathrm{TSEB}_{\mathrm{CT}}$ and $\mathrm{TSEB}_{\mathrm{PT}}$ flux outputs at ASTER overpass time and EC measurements (adjusted observations by Bowen ratio (BR) and residual (R) approaches for energy balance closure, respectively) and LAS measurements $\left(\mathrm{W} / \mathrm{m}^{2}\right)^{\mathrm{a}}$.

\begin{tabular}{cccccccc}
\hline \multirow{2}{*}{ Flux } & Mean & \multicolumn{3}{c}{ TSEB $_{\mathrm{CT}}$} & \multicolumn{3}{c}{ TSEB $_{\text {PT }}$} \\
& Obs. & Mean Bias & MAP & RMSE & Mean Bias & MAP & RMSE \\
\hline$R n$ & 646 & -14 & $4.5 \%$ & 37 & -9 & $4.5 \%$ & 38 \\
$G$ & 89 & 5 & $40.6 \%$ & 42 & 1 & $31.3 \%$ & 36 \\
$H(B R)$ & 120 & -26 & $36.7 \%$ & 56 & -59 & $56.0 \%$ & 79 \\
$L E(B R)$ & 437 & 3 & $9.3 \%$ & 52 & 50 & $15.2 \%$ & 87 \\
$H(R)$ & 94 & -5 & $30.7 \%$ & 40 & -42 & $47.7 \%$ & 56 \\
$L E(R)$ & 462 & -21 & $10.5 \%$ & 58 & 25 & $11.7 \%$ & 71 \\
$H(L A S)$ & 127 & -27 & $24 \%$ & 36 & -61 & $46 \%$ & 67 \\
\hline
\end{tabular}

${ }^{a}$ Mean Bias is the average value of the modeled fluxes - observed fluxes; MAP is mean absolute percentage (average of absolute difference between modeld and measured fluxes divided by average measured flux) and RMSE is root mean square error (square root of the sum of the differences between modeled and measured fluxes squared divided by the number of observations).

For $H$, the TSEB ${ }_{\mathrm{CT}}$ model tended to underestimate when $\mathrm{EC}$ measurements were adjusted using the Bowen ratio closure technique, while there was little bias when $H$ was not adjusted suing the residual approach. The bias in $H$ with TSEB PT $_{\text {T }}$ is more pronounced, especially when the Bowen ratio closure is applied for adjusting the EC measurements of $H$. The closure approach has the largest affect on model-observation agreement for the residential site where there is either a significant under or overestimate in $L E$ (Fig. 3 e, f, i, j). The difference statistics listed in Table 1 indicate that the overall performance of both models are similar for $L E$, and that the MAP values are within the $\sim 15 \%$ uncertainty in the measured $L E$ (Wang et al., 2014). 


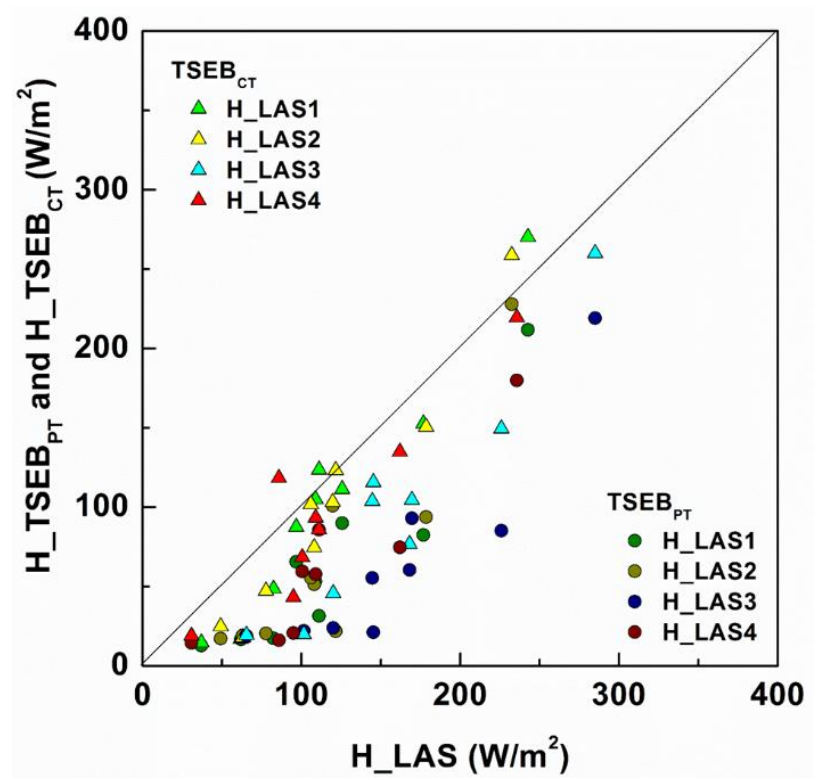

Fig. 4. Comparison of surface sensible heat fluxes observed from LAS and modeled from TSEB PT $_{\text {and }}$ TSEB $_{\mathrm{CT}}$ during the HiWATER at times of ASTER overpass.

The sensible heat flux output from the $\mathrm{TSEB}_{\mathrm{PT}}$ and $\mathrm{TSEB}_{\mathrm{CT}}$ were also compared to the four pairs LAS flux measurements. The larger flux footprint area associated with the LAS measurements offered an opportunity to integrate a significant number of pixels of $H$ computed by $\mathrm{TSEB}_{\mathrm{PT}}$ and $\mathrm{TSEB}_{\mathrm{CT}}$ models and hence reduce some of the noise and uncertainty inherent in representativeness of the flux tower measurements to the local conditions. The comparison of sensible heat fluxes observed from LAS and modeled from TSEB ${ }_{\mathrm{PT}}$ and TSEB $_{\mathrm{CT}}$ are illustrated in Fig. 4 from the figure it appears that the estimates of $H$ from $\mathrm{TSEB}_{\mathrm{CT}}$ are generally in closer agreement with the 30-min-average $H$ from the LAS measurements at the satellite overpass times than the $\mathrm{TSEB}_{\mathrm{PT}}$ model output. The TSEB $\mathrm{CT}_{\mathrm{C}}$ model yields a mean bias, MAP, and RMSE value of $-27 \mathrm{~W} / \mathrm{m}^{2}$ and $24 \%, 36 \mathrm{~W} / \mathrm{m}^{2}$, respectively, while model-measured differences from $\mathrm{TSEB}_{\mathrm{PT}}$ are $-61 \mathrm{~W} / \mathrm{m}^{2}$ and $46 \%, 67 \mathrm{~W} / \mathrm{m}^{2}$, respectively. However, particularly for the LAS3 observations both of the models produce significantly greater differences with the measurements. According to a field investigation there were more residential areas randomly distributed in the LAS3 source area (Fig. 1) than other three LAS systems resulting in greater uncertainty in specifying inputs to the LAS computations for $H$ and also resulting in greater variations in land surface moisture and temperature and roughness conditions all of 19 
which affect TSEB model output.

By its design, the TSEB models provide estimates of the soil and vegetation canopy component fluxes and consequently the evaporation for the surface soil $(E)$ and transpiration from plants $(T)$. There have been few studies that have reliable $E$ and $T$ measurements to evaluate TSEB. In the current study, the ratios of E/ET and T/ET were measured using the stable oxygen and hydrogen isotopes technology at site 13 and 15, both located under corn land cover during the HiWATER-MUSOEXE. The measurements on DOY 192 and 215 at station 13 and on DOY 167, 176, 192, $215,224,231,240$ and 256 at site 15 were selected to evaluate the model performance. Comparison of E/ET and T/ET between the model output and ground measurements shows that $\mathrm{TSEB}_{\mathrm{CT}}$ estimates yield better agreement overall with mean bias of $6.4 \%$ for E/ET\% (-6.4\% for T/ET\%) while $\mathrm{TSEB}_{\mathrm{PT}}$ value is $18.7 \%$ for E/ET\% (-18.7\% for T/ET\%). Thus $\mathrm{TSEB}_{\mathrm{PT}}$ more significantly than $\mathrm{TSEB}_{\mathrm{CT}}$ overestimates E/ET and underestimates T/ET, similar to the results given by Colaizzi et al (2102). The comparisons between the model estimation and ground measurement at station 15 (a corn site) are illustrated in Fig. 5 along with surface soil moisture $(4 \mathrm{~cm}$ depth) and green vegetation cover fraction. The E/ET ratio estimate by $\mathrm{TSEB}_{\mathrm{CT}}$ model has a similar seasonal variation and is in agreement with the ground measurements until later in the growing season, when the crop is undergoing senescence (after DOY 245). The $\mathrm{TSEB}_{\mathrm{PT}}$ output of E/ET was significantly higher during the entire growing season and only approached measured values of E/ET at the end of the growing season. The temporal trend in surface soil moisture, however, was not always reflected in the observed variation in E/ET. Thus there is clearly uncertainty in the observed E/ET values as well. However, later in the season, the E/ET \% values of both modeled and observed increased as the crops underwent senescence but the soil remained relatively moist. 


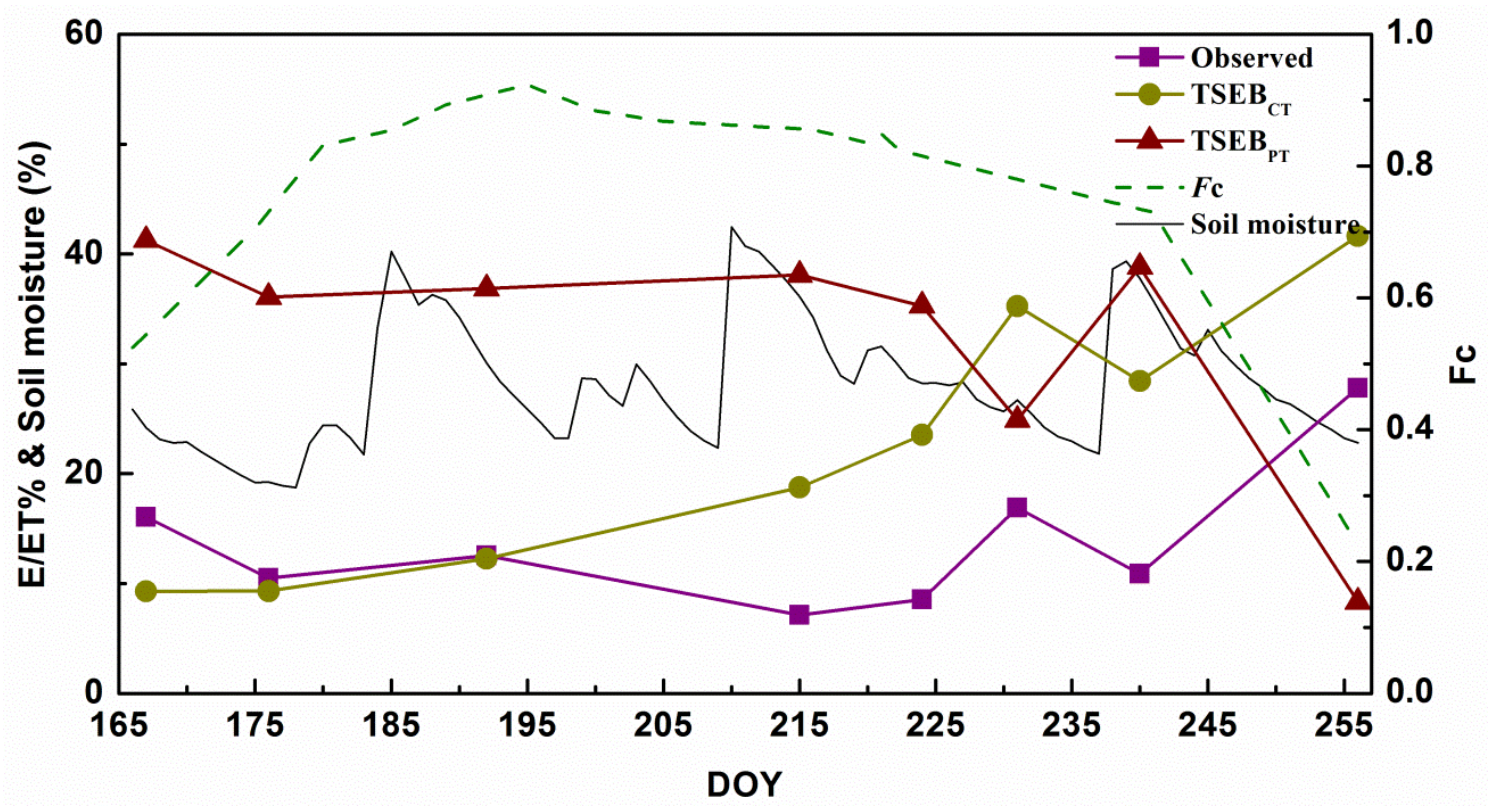

Figure. 5. Comparison of the E/ET (\%) between model estimates and ground measurements. Also the percentage soil moisture (solid black line) and fractional green vegetation cover $(\mathrm{Fc})$ for the corn crop at flux station 15 .

\subsection{Model intercomparison of spatially distributed LE}

Validation of model output using towers flux measurements is a very common approach for assessing the utility of ET models. However, tower measurements will not cover all the different landscape conditions including the variation in amount of vegetation cover even if the major land cover types are being monitored in a region. Model inter-comparisons over a satellite scene typically contain a wider range of surface conditions providing unique insights as to how different models predictions are affected by land characteristics (Cammalleri et al., 2012; Timmermans et al., 2007). To have a more fundamental understanding of how the two models respond to different surface conditions across a landscape, an analysis of the spatial distributions and magnitude of the surface fluxes produced from the TSEB $_{\mathrm{CT}}$ and $\mathrm{TSEB}_{\mathrm{PT}}$ models was conducted. Two days (DOY176 and 192) were selected based on different atmospheric conditions, crop growth stages and surface soil moisture conditions that existed and assumed to strongly influence model output (Fig. 6). The output of $L E$ for the two days indicate a consistency in the spatial variations/patterns of instantaneous $L E$ from the two models for the range of environmental conditions (fractional vegetation cover and soil moisture) existing in these scenes. 


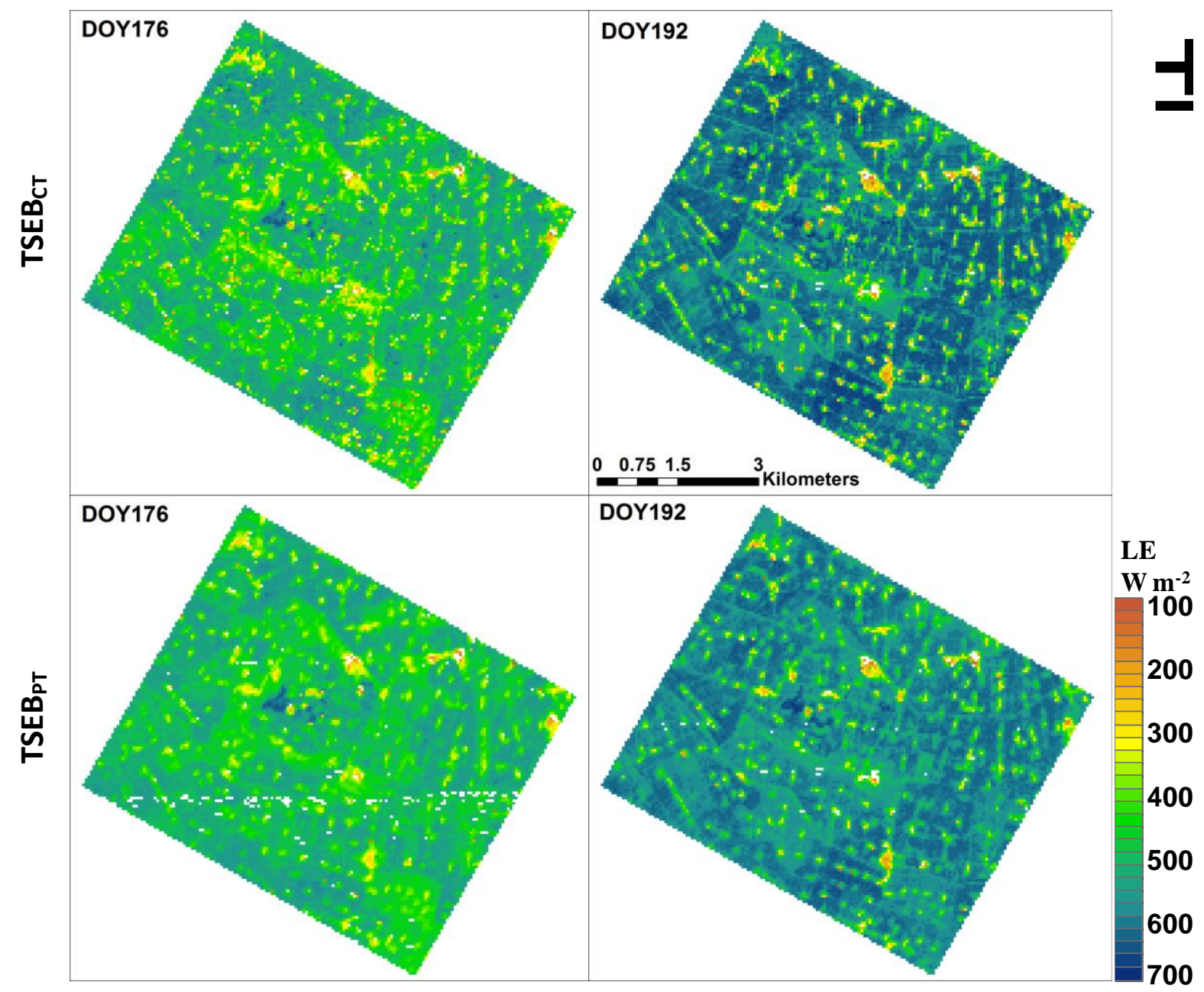

Fig. 6. Comparison of $\mathrm{TSEB}_{\mathrm{CT}}$ and $\mathrm{TSEB}_{\mathrm{PT}}$ model output: spatial distribution of instantaneous LE under different conditions.

There is a similar spatial distribution of estimated $L E$ from the two models, namely, higher in croplands but lower in the residential sites (Fig. 4). In addition, the figure also illustrates a range in $L E$ values across the cropland areas, which is associated with different fractional vegetation cover and soil moisture conditions for individual pixels and fields. The two models compute similar $L E$ values for the residential area as well as for the cropland and orchard sites. However, TSEB ${ }_{\mathrm{CT}}$ tended to have a greater range in $L E$ values in comparison with the output from the TSEB $_{\mathrm{PT}}$ model (Fig. 7). In both the cropland and orchard land covers there are pixels from the $\mathrm{TSEB}_{\mathrm{CT}}$ where $L E$ is under $200 \mathrm{~W} / \mathrm{m}^{2}$ while the output from $\mathrm{TSEB}_{\mathrm{PT}}$ rarely goes below $300 \mathrm{~W} / \mathrm{m}^{2}$. Differences in $L E$ between the two models exceeding 100 $\mathrm{W} / \mathrm{m}^{2}$ (greater than the $15 \%$ uncertainty in measured $L E$ from the EC towers in this 
study area) are illustrated as red points in the scatter plots (Fig. 7). In addition, where these extreme differences occur on the image is also illustrated in Fig. 8. This plot suggests the major $L E$ discrepancies between the models tend to be near the borders with urban/residential areas.
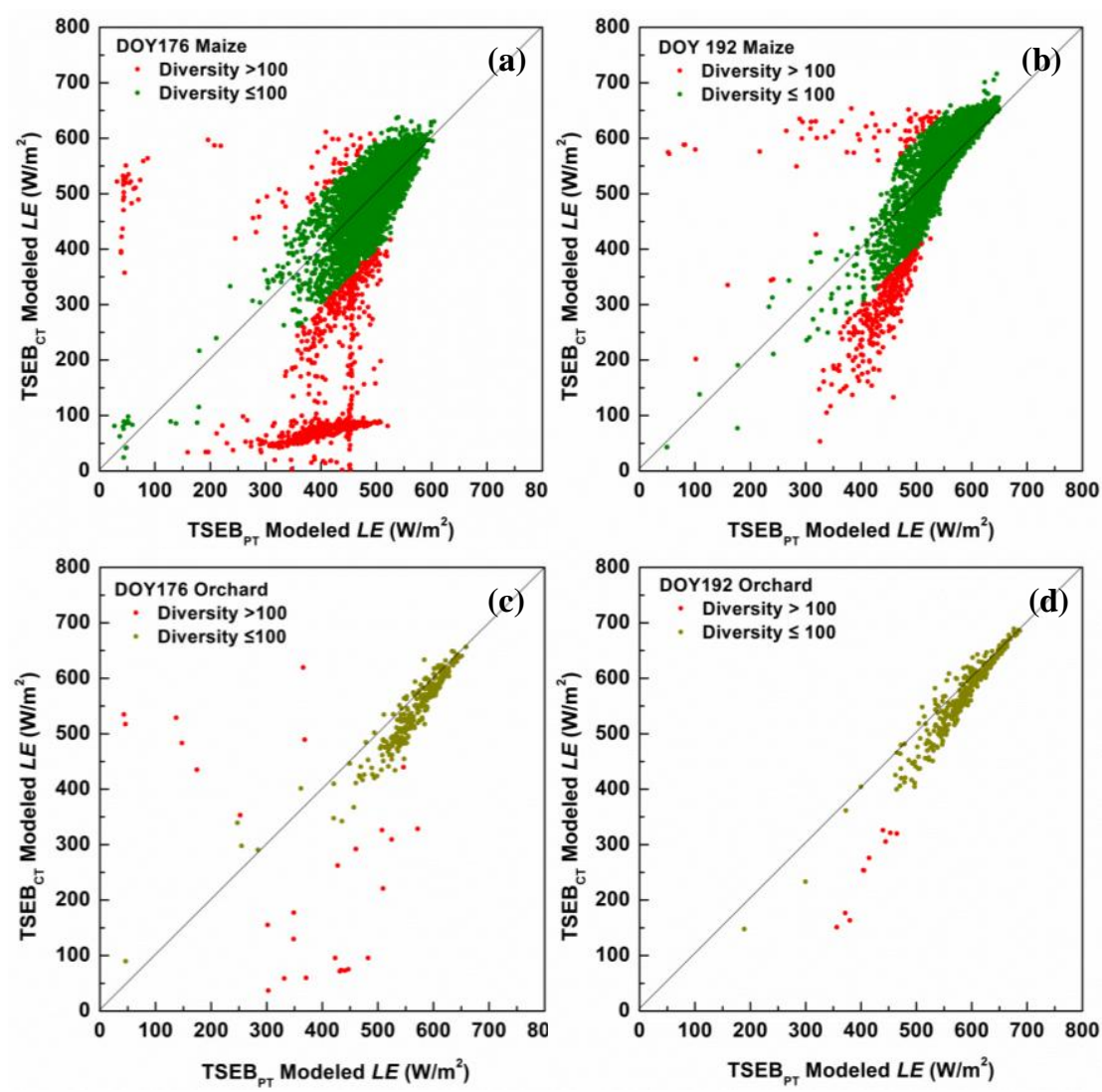

Fig. 7. Comparison of $L E$ output from $\mathrm{TSEB}_{\mathrm{CT}}$ and $\mathrm{TSEB}_{\mathrm{PT}}$ models using remote sensing data on DOY 176 and DOY 196 in 2012. Panels (a), (b) and (c), (d) are comparisons of TSEB CT $_{\text {and TSEB }}$ model output of $L E$ under corn and orchard land covers, where the red points indicate model differences exceed $100 \mathrm{~W} / \mathrm{m}^{2}$. 


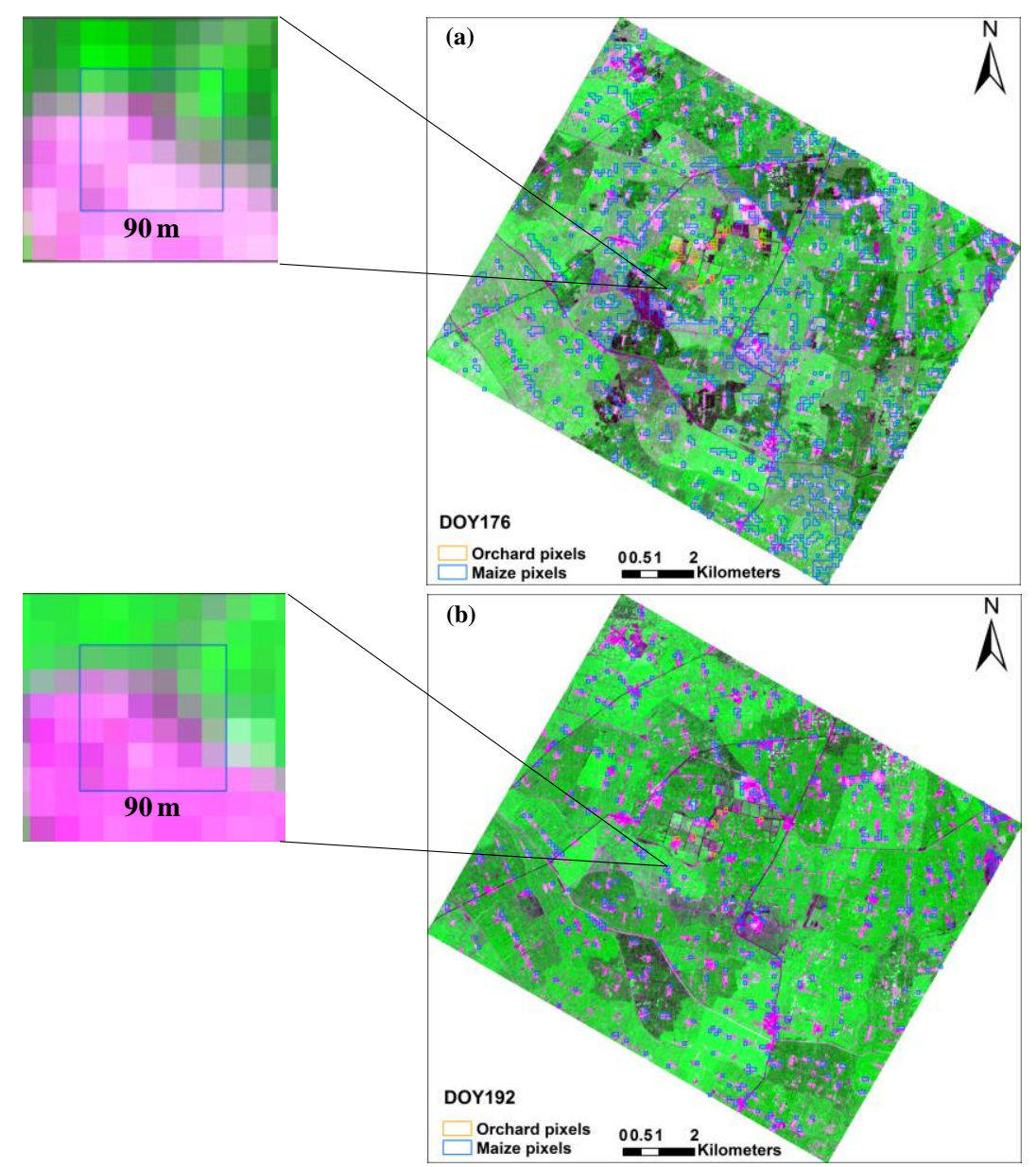

Fig. 8. Illustrations area of modeled $L E$ differences between TSEB $_{\mathrm{CT}}$ and TSEB $_{\mathrm{PT}}$ models on DOY 176 and DOY 196 in 2012. panels (a) and (b) demark the areas (within the blue and yellow boundaries) where the two models differ by more than $100 \mathrm{~W} / \mathrm{m}^{2}$ using the $15 \mathrm{~m}$ resolution RGB (Red, Green Blue bands consisting of band 2,3, and 1) imagery.

\section{Summary and Conclusions}

Accurate estimation of surface fluxes, especially the components $E$ and $T$ from remote sensing data is a challenging task. Here, two remote sensing-based models $\mathrm{TSEB}_{\mathrm{CT}}$ and $\mathrm{TSEB}_{\mathrm{PT}}$ were applied to map regional surface fluxes using the component and composite land surface temperatures, respectively. In general the performance of the two models are similar for the four energy balance components $R n, G_{0}, H$ and $L E$, but there were larger differences or bias for certain land cover types which were dependent on the energy balance closure technique adopted. Measurements of component fluxes $E$ and $T$ indicated that TSEB $_{\mathrm{PT}}$ tended to produce greater (lower) E/ET (T/ET) ratios than observed. This agrees with Colaizzi et al's 
findings (2012a). Although TSEB $_{\mathrm{CT}}$ showed a similar bias, they were considerably less than the output from TSEB PT.

For this study area, model differences in $L E$ exceeding $100 \mathrm{~W} / \mathrm{m}^{2}$ (which is greater than the $15 \%$ uncertainty in the EC measurements) between $\mathrm{TSEB}_{\mathrm{PT}}$ and $\mathrm{TSEB}_{\mathrm{CT}}$, appeared in some cropland and orchard pixels. The associated pixels illustrated in the $15 \mathrm{~m}$ RGB land use maps on DOY 176 and DOY 192 (Fig. 8) indicate these areas of large $L E$ discrepancies are mixed pixels at the $90 \mathrm{~m}$ resolution comprised of some fraction of cropland, residential and road, but are often classified as simply cropland or residential. Ground measurements from the component radiometer at the residential site and that from thermal camera in corn field showed that the surface soil temperatures can differ by more than $20 \mathrm{~K}$ between urban/road and cropland at noon time. According to the ground measurements from EC system located in the residential/urban site surrounded by crop fields and trees, the $L E$ was around $200 \mathrm{~W} / \mathrm{m}^{2}$ at satellite overpass times for both days (DOY 176 and 192). The TSEB $_{\mathrm{PT}}$ model values averaged around $400 \mathrm{~W} / \mathrm{m}^{2}$ while $L E$ estimates from the $\mathrm{TSEB}_{\mathrm{CT}}$ model were around $280 \mathrm{~W} / \mathrm{m}^{2}$. This clearly points to the issue that applying models over strongly heterogeneous pixels can lead to large uncertainty in flux estimation that is not easily validated with ground measurements. Model refinements to address mixed pixel issue are clearly needed, as errors from landcover data cannot be avoided. For instance the current widely used MODIS landcover product has an uncertainty of about 25\% (Fredl et al., 2010).

Although the output of $H$ and $L E$ from TSEB $_{\mathrm{CT}}$ yielded closer agreement in general with EC and LAS measurements than $\mathrm{TSEB}_{\mathrm{PT}}$, the algorithms for partitioning soil and vegetation temperatures from thermal-infrared data from single view angle sensor observation have not been validated for other landcover and climate conditions, which currently limits the routine application of $\mathrm{TSEB}_{\mathrm{CT}}$ model to other landscapes.

Future studies should address how to estimate reliable soil and vegetation component temperatures from the remote sensing data supplied from the sensors with single view angle and multi-angular observations. More studies using muti-scale remote sensing data over arid and semi-arid landscapes where water stress would be 25 
more prevalent are required and need to include measurements of $E T$ and $E$ and $T$ for evaluating the capability of accurate energy flux partitioning.

\section{Acknowledgements}

We thank all the scientists, engineers, and students who participated in HiWATER field campaigns. This work was supported by the National Natural Science Foundation of China (91125002 and 41531174). We would like to thank Professor Xuefa Wen at Synthesis Research Center of China Ecosystem Research Network, Key Laboratory of Ecosystem Network Observation and Modeling, Institute of Geographic Science and Natural Resource, Chinese Academy of Science, Beijing China. USDA is an equal opportunity employer and provider.

\section{Reference:}

Agam, N., Kustas, W.P., Anderson, M.C., Norman, J.M., Colaizzi, P.D., Howell, T.A., Prueger, J.H., Meyers, T.P., Wilson, T.B., 2010. Application of the Priestley-Taylor Approach in a Two-Source Surface Energy Balance Model. J. Hydrometeorol., 11, 185-198.

Agam, N., Evett, S.R., Tolk, J.A., Kustas, W.P., Colaizzi, P.D., Alfieri, J.G., McKee, L.G., Copeland, K.S., Howell, T.A., Chávez, J.L. 2012. Evaporative loss from irrigated interrows in a highly advective semi-arid agricultural area. Adv. Water. Resour., 50, 20-30.

Allen, R.G., Tasumi, M., Trezza, R., 2007. Satellite-Based Energy Balance for Mapping Evapotranspiration with Internalized Calibration (METRIC)—Model. J. Irrig. Drain. Engineering., 133, 380-394.

Anderson, M.C., Norman, J.M., Diak, G.R., Kustas, W.P., Mecikalski, J.R., 1997. A two-source time-integrated model for estimating surface fluxes using thermal infrared remote sensing. Remote. Sens. Environ., 60, 195-216.

Bastiaanssen, W.G.M., Menenti, M., Feddes, R.A., Holtslag, A.A.M., 1998. A remote sensing surface energy balance algorithm for land (SEBAL). 1. Formulation. J. Hydrol., 212-213, 198-212.

Cammalleri, C., Anderson, M.C., Ciraolo, G., D'Urso, G., Kustas, W.P., La Loggia, G., Minacapilli, M., 2012. Applications of a remote sensing-based two-source energy balance algorithm for mapping surface fluxes without in situ air temperature observations. Remote. Sens. Environ., 124, 502-515.

Choi, M., Kustas, W.P., Anderson, M.C., Allen, R.G., Li, F., Kjaersgaard, J.H., 2009. An intercomparison of three remote sensing-based surface energy balance algorithms over a corn and soybean production region (Iowa, U.S.) during SMACEX. Agric. For. Meteorol., 149, 2082-2097.

Colaizzi, P.D., Kustas, W.P., Anderson, M.C., Agam, N., Tolk, J.A., Evett, S.R., Howell, T.A., Gowda, P.H., O'Shaughnessy, S.A., 2012a. Two-source energy balance model estimates of evaportranspiration using component and composite surface temperatures. Adv. Water. Resour., 50, 134-151.

Colaizzi, P.D., Evett, S.R., Howell, T.A., Li, F.Q., Kustas, W.P., Anderson, M.C., 2012b. Radiation Model for Row Crops: I. Geometric View Factors and Parameter Optimization. Agron. J., 104, 225-240.

Colaizzi, P.D., Schwartz, R.C., Evett, S.R., Howell, T.A., Gowda, P.H., Tolk, J.A., 2012c. Radiation 
Model for Row Crops: II. Model Evaluation. Agron. J., 104, 241-255.

Friedl, M. A. ,Sulla-Menashe D., Tian B., Schneider A., Ramankutty N., Sibley A., Huang X.M., 2010. MODIS Collection 5 global land cover: Algorithm refinements and characterization of new datasets, Remote. Sens. Environ.,114, 168-182.

Foken T., 2008. The energy balance closure problem: an overview. Ecol. Appl., 18, 1351-1367.

Foken T., Aubinet M., Finnigan J., Leclerc M., Mauder M., Paw., U. K. T., 2011. Results of a panel discussion about the energy balance closure correction for trace gases. Bull. Am. Meteorol. Soc. 92. ES13-ES18.

Hsieh C., Gabriel Katul G., Chi T., 2000. An approximate analytical model for footprint estimation of scalar fluxes in thermally stratified atmospheric flows. Adv. Water. Resour., 23,765-772.

Hu, Z.M., Wen, X.F., Sun, X.M., Li, LH.,, Yu, G.R., Lee, X.H., Li, S.G., 2014. Partitioning of evapotranspiration through oxygen isotopic measurements of water pools and fluxes in a temperate grassland. J. Geophys. Res.: Biogeosciences, 119, 358-372.

Huang, L.J., Wen, X.F., 2014. Temporal variations of atmospheric water vapor $\delta \mathrm{D}$ and $\delta 18 \mathrm{O}$ above an arid artificial oasis cropland in the Heihe River Basin. J. Geophys. Res.: Atmospheres, 119, 11456-11476.

Jia, Z.Z., Liu, S.M., Xu, Z.W., Chen, Y.J., Zhu, M.J., 2012. Validation of remotely sensed evapotranspiration over the Hai River Basin, China. J Geophys Res: Atmospheres, 117, D13113. DOI: 10.1029/2011JD017037

Kustas, W., Anderson, M., 2009. Advances in thermal infrared remote sensing for land surface modeling. Agric. For. Meteorol., 149, 2071-2081.

Kustas, W.P., Norman, J.M., 1999. Evaluation of soil and vegetation heat flux predictions using a simple two-source model with radiometric temperatures for partial canopy cover. Agric. For. Meteorol., 94, 13-29.

Kustas, W.P., Norman, J.M., 2000. A Two-Source Energy Balance Approach Using Directional Radiometric Temperature Observations for Sparse Canopy Covered Surfaces. Agron. J., 92, 847-854.

Kustas W P., Norman, J. M. , Schmugge, T. J., Anderson, M. C., 2004. Mapping surface energy fluxes with radiometric temperature. Chapter 7 in: Thermal Remote Sensing in Land Surface Processes (Editors D. Quattrochi and J. Luvall), pp. 205-253. CRC Press Boca Raton, Florida, USA.

Li, X., Cheng, G.D., Liu, S.M., Xiao, Q., Ma, M.M., Jin, R., Che, T., Liu, Q.H., Wang, W.Z., Qi, Y., Wen, J.G., Li, H.Y., Zhu, G.F., Guo, J.W., Ran, Y.H., Wang, S.G., Zhu, Z.L., Zhou, J., Hu, X.L., Xu, Z.W., 2013. Heihe Watershed Allied Telemetry Experimental Research (HiWATER): Scientific Objectives and Experimental Design. B. Am. Meteorol. Soc., 94, 1145-1160.

Liang, S.L., 2001. Narrowband to broadband conversions of land surface albedo I: Algorithms. Remote. Sens. Environ., 76, 213-238.

Liebethal, C., Huwe, B., Foken., T., 2005. Sensitivity analysis for two ground heat flux calculation approaches. Agric. For. Meteorol., 132, 253-262.

Liu, S.M., Xu, Z.W., Wang, W.Z., Jia, Z.Z., Zhu, M.J., Bai, J., Wang, J.M., 2011. A comparison of eddy-covariance and large aperture scintillometer measurements with respect to the energy balance closure problem. Hydrol. Earth Syst. Sci., 15, 1291-1306.

Liu, S.M., Xu, Z.W., Zhu, Z.L., Jia, Z.Z., Zhu, M.J., 2013. Measurements of evapotranspiration from eddy-covariance systems and large aperture scintillometers in the Hai River Basin, China. J. Hydrol., 487, 24-38.

Liu, S.M., Xu, Z.W., Zhao, Q.Y., Xu, T.R., Ge, Y., Ma, Y.F., Song, L.S., Zhu Z.L., Jia, Z.Z., Zhang F., 
Upscaling evapotranspiration measurements from multi-site to the satellite pixel scale over heterogeneous land surfaces, Agric. For. Meteorol., Under Review.

Ma Y.F., Liu S.M., Zhang F., Zhou J., Jia Z.Z., Song L.S., 2015. Estimations of Regional Surface Energy Fluxes Over Heterogeneous Oasis-Desert Surfaces in the Middle Reaches of the Heihe River During HiWATER-MUSOEXE, IEEE Geosci. Remote S., 12, 671-675.

Mu, X.H., Hu, R.H., Huang, S., Chen, Y.M., 2013. HiWATER: Dataset of emissivity in the middle reaches of the Heihe River Basin in 2012. Heihe Plan Science Data Center

Norman, J.M., Anderson, M.C., Kustas, W.P., French, A.N., Mecikalski, J., Torn, R., Diak, G.R., Schmugge, T.J., Tanner, B.C.W., 2003. Remote sensing of surface energy fluxes at 101-m pixel resolutions. Water. Resour. Res., 39, 1221.

Norman, J.M., Kustas, W.P., Humes, K.S.,1995. Source approach for estimating soil and vegetation energy fluxes in observations of directional radiometric surface temperature. Agric. For. Meteorol., 77, 263-293.

Norman, J.M., Kustas, W.P., Prueger, J.H., Diak, G.R., 2000. Surface flux estimation using radiometric temperature: A dual-temperature-difference method to minimize measurement errors. Water. Resour. Res. 36, 2263-2274

Pereira, L.S., Allen, R.G., Smith, M., Raes, D., 2015. Crop evapotranspiration estimation with FAO56: Past and future. Agr. Water Manage., 147, 4-20.

Priestley, C.H.B., Taylor, R.J., 1972. On the Assessment of Surface Heat Flux and Evaporation Using Large-Scale Parameters. Mon.Weather. Review., 100, 81-92.

Sánchez, J.M., Kustasa, W.P., Casellesb, V., Andersona, M.C., 2008. Modelling surface energy fluxes over maize using a two-source patch model and radiometric soil and canopy temperature observations. Remote. Sens. Environ., 112, 1130-1143.

Sánchez, J.M., López-Urrea R., Doña,C., Caselles, V., González-Piqueras, J., Niclòs, R., 2015. Modeling evapotranspiration in a spring wheat from thermal radiometry: crop coefficients and $\mathrm{E} / \mathrm{T}$ partitioning. Irrigation Science, 33, 399-410.

Scanlon, T.M., Kustas, W.P., 2012. Partitioning Evapotranspiration Using an Eddy Covariance-Based Technique: Improved Assessment of Soil Moisture and Land-Atmosphere Exchange Dynamics. Vadose. Zone. J.,11, vzj2012.0025.

Sobrino, J.A., Jiménez-Muñoz, J.C., Paolini, L., 2004. Land surface temperature retrieval from LANDSAT TM 5. Remote. Sens. Environ., 90, 434-440.

Song, L.S., Liu, S.M., Zhang, X., Zhou, J., Li, M.S., 2015a. Estimating and Validating Soil Evaporation and Crop Transpiration During the HiWATER-MUSOEXE. IEEE Geosci. Remote S., 12, 334-338

Song, L.S., Liu S.M., Kustas W.P. Zhou J., Ma Y.F., 2015b. Using the Surface Temperature-Albedo Space to Separate Regional Soil and Vegetation Temperatures from ASTER Data. Rmeote. Sens-basel., 7, 5828-5848.

Su, Z.B., 2002. The Surface Energy Balance System (SEBS) for estimation of turbulent heat fluxes. Hydrol. Earth Syst. Sci., 6, 85-100.

Timmermans, W.J., Kustas, W.P., Anderson, M.C., French, A.N., 2007. An intercomparison of the Surface Energy Balance Algorithm for Land (SEBAL) and the Two-Source Energy Balance (TSEB) modeling schemes. Remote. Sens. Environ. 108, 369-384.

Twine, T.E., Kustas, W.P., Norman, J.M., Cook, D.R., Houser, P.R., Meyers, T.P., Prueger, J.H., Starks, P.J., Wesely, M.L., 2000. Correcting eddy-covariance flux underestimates over a grassland. Agric. For. 
Meteorol., 103, 279-300.

Wang, J.M., Zhuang, J.X., Wang, W.Z., Liu, S.M., Xu, Z.W., 2015. Assessment of Uncertainties in Eddy Covariance Flux Measurement Based on Intensive Flux Matrix of HiWATER-MUSOEXE. IEEE Geosci. Remote S., 12, 259-263.

Wen, X.F., Lee, X.H., Sun, X.M., Wang, J.L, Hu, Z.M., Li, S.G., Yu, G.R., 2012. Dew water isotopic ratios and their relationships to ecosystem water pools and fluxes in a cropland and a grassland in China. Oecologia., 168, 549-561.

Wen X.F., Yang B., Sun X.M., Lee X.H., 2015. Evapotranspiration partitioning through in-situ oxygen isotope measurements in an oasis cropland, Agric. For. Meteorol., under review.

Xu, Z.W., Liu, S.M., Li, X., Shi, S.J., Wang, J.M., Zhu, Z.L., Xu, T.R., Wang, W.Z., Ma, M.G., 2013. Intercomparison of surface energy flux measurement systems used during the HiWATER-MUSOEXE. J. Geophys. Res.: Atmospheres,118, 13,140-113,157.

Zhou, J., Li, M.S., Liu, S.M., Jia, Z.Z., Ma, Y.Y., 2015. Validation and Performance Evaluations of Methods for Estimating Land Surface Temperatures from ASTER Data in the Middle Reach of the Heihe River Basin, Northwest China. Remote Sens-basel., 7, 7126-7156. 